\title{
Correction to: A Dual-Type Electrochromic Device Based on Complementary Silica/Conducting Polymers Nanocomposite Films for Excellent Cycling Stability
}

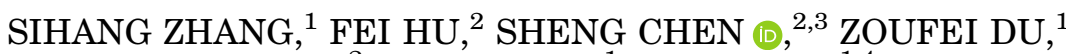 \\ HONGCHAO PENG, ${ }^{2}$ FENG YANG ${ }^{1}$ and $\mathrm{YA} \mathrm{CAO}^{1,4}$ \\ 1.-State Key Laboratory of Polymer Materials Engineering, Polymer Research Institute of \\ Sichuan University, Chengdu 610065, China. 2.-Functional Polymer Materials Laboratory, \\ College of Light Industry, Textile and Food Engineering, Sichuan University, \\ Chengdu 610065, China. 3.—e-mail: chensheng@scu.edu.cn. 4.—e-mail: caoya@scu.edu.cn
}

\section{CORRECTION TO:}

JOURNAL OF ELECTRONIC MATERIALS, VOL. 48, NO. 8, 2019

HTTPS://DOI.ORG/10.1007/S11664-019-07273-9

In the original article, there is an error in Fig. 2.

Following is the corrected Fig. 2. 
A Dual-Type Electrochromic Device Based on Complementary Silica/Conducting Polymers Nanocomposite Films for Excellent Cycling Stability
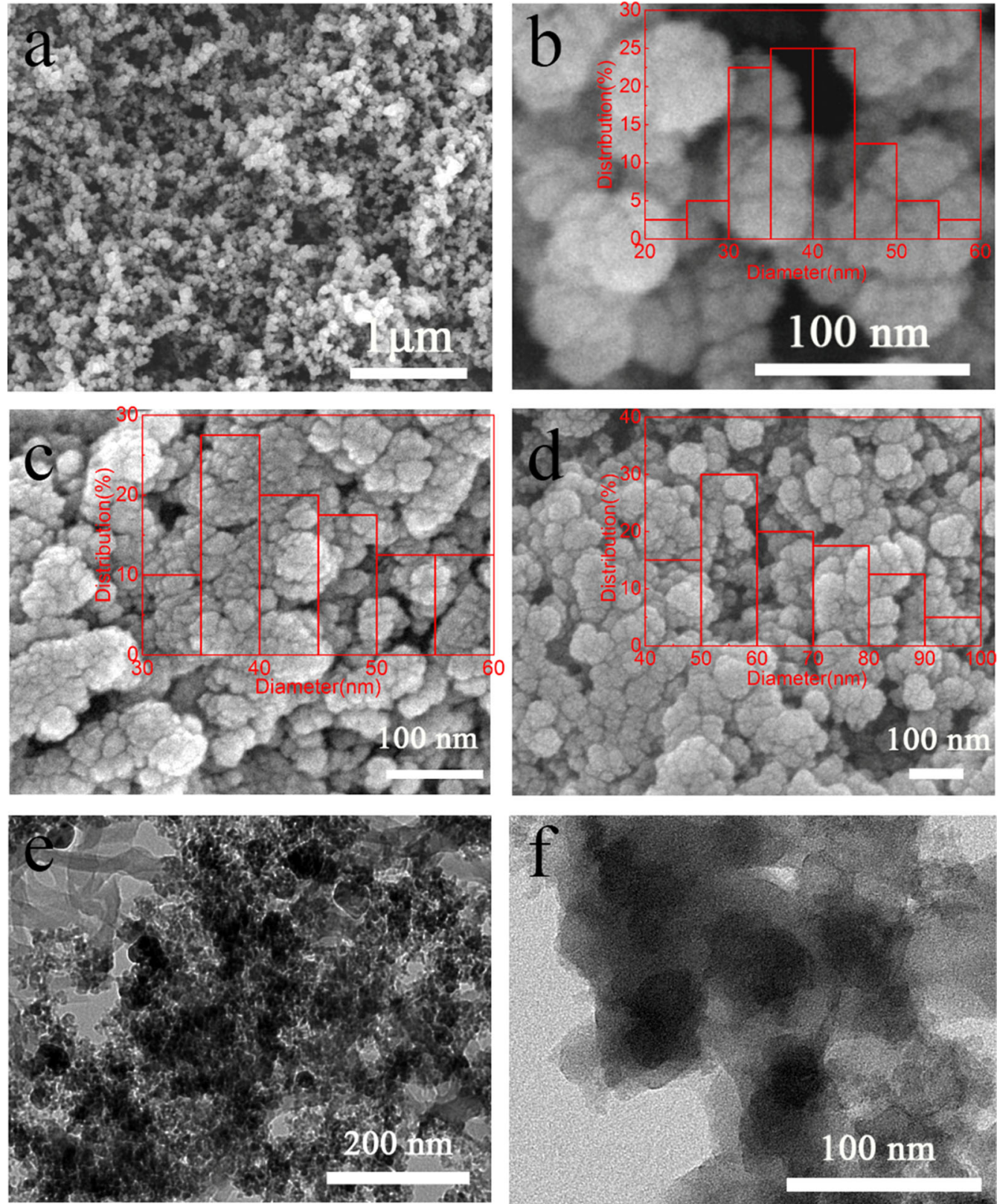

Fig. 2. SEM images of $\mathrm{SiO}_{2}$ nanoparticles (a, b), $\mathrm{SiO}_{2} / \mathrm{PANI}$ (c) and $\mathrm{SiO}_{2} / \mathrm{PEDOT}$ (d) nanocomposites. These insets are the diameter distributions of $\mathrm{SiO}_{2}, \mathrm{SiO}_{2} / \mathrm{PANI}$ and $\mathrm{SiO}_{2} /$ PEDOT. TEM images of $\mathrm{SiO}_{2} / \mathrm{PANI}$ (e) and $\mathrm{SiO}_{2} / \mathrm{PEDOT}$ (f) nanocomposites.

Publisher's Note Springer Nature remains neutral with regard to jurisdictional claims in published maps and institutional affiliations. 